\title{
Editorial
}

\section{Opening the window of opportunity: encouraging patients to stop smoking}

Smoking is a complex behaviour involving physiological dependence on regular administration of nicotine, psychological dependence to cope with stress, and reinforcement in social contexts. Smoking cessation is difficult.

\section{Evidence for intervening with smokers}

Physicians inform patients about the overwhelming evidence demonstrating the cardiovascular hazards of tobacco use and the health benefits from smoking cessation, but many continue to smoke. Smoking contributes to approximately $30 \%$ of all ischaemic heart disease deaths (IHD) in the USA each year, and the risk is strongly dose related. ${ }^{12}$ Smoking acts synergistically with other risk factors leading to an increased risk of IHD, ${ }^{3}$ as well as nearly doubling the risk of ischaemic stroke. ${ }^{4}$ At age 30-49 years the rates of myocardial infarction in smokers are five times those of non-smokers; at 50-59 they are three times those of non-smokers; and at 60-79 they are twice as great as for non-smokers. ${ }^{5}$ About half of those who smoke are killed by their habit, whereas among never and ex-smokers, $80 \%$ survive to 70 and $33 \%$ to 85 years old. ${ }^{6}$

An adverse cardiac condition or cardiac interventional procedure encourages smokers to quit their habit. ${ }^{78}$ Among patients with coronary artery disease, the likelihood of cessation from smoking increases with the severity of symptoms and signs of disease..$^{9-11}$ Patients with unstable angina are more likely to quit smoking than those with stable angina. ${ }^{12}$ The rate of smoking cessation in patients with angiographically confirmed coronary artery disease varies from $35 \%$ to $75 \% .^{9-11}{ }^{13}$ Providing smoking cessation advice to patients who have been hospitalised with a coronary condition results in a 50\% long term (more than one year) abstinence rate. ${ }^{74}$ Abstinence at one year is achieved in two thirds of smokers after percutaneous coronary revascularisation and advice from physicians using a comprehensive risk factor intervention and regular follow up. ${ }^{15}$ When patients with IHD quit smoking they have a $50 \%$ reduction in risk of reinfarction, sudden cardiac death, and total mortality after the initial infarction. ${ }^{16-18}$

However, despite the proved benefits of smoking cessation after percutaneous coronary revascularisation, many patients continue to smoke after the procedure. ${ }^{12}{ }^{19}$ Additionally, smokers at one year following coronary bypass surgery had more than twice the risk for myocardial infarction and reoperations than never and ex-smokers; the risk was also higher at five years. ${ }^{20}$

\section{Clinical approaches}

Two decades of clinical trials conducted in general practice have demonstrated that the general practitioner has a major role to play in tobacco control, and there is a strong, positive dose-response relation between both intensity and duration of treatment and successful cessation. ${ }^{21}$ When a general practitioner gives very brief advice to quit and a pamphlet on smoking cessation strategies, this yields $5-10 \%$ abstinence at one year. ${ }^{22-24}$ With longer and more intensive intervention including strategies for quitting, nicotine replacement treatment, and follow up visits, cessation rates of $15-36 \%$ at one year are achieved. ${ }^{25-28}$ These cessation rates are much greater than the $4 \%$ maintained in the general population. ${ }^{21}$

There are several smoking cessation guidelines for medical practitioners - for example, the Agency for Health Care Policy and Research (AHCPR) guideline is based on evidence from more than 300 published studies. ${ }^{21}$ The "Smokescreen program" described below is a programme used by general practitioners in Australia and New Zealand, and has been promoted to physicians through the Royal Australasian College of Physicians. ${ }^{29}$ In our studies in general practice with more involved interventions conducted among healthy smokers with no IHD and with varying degrees of motivation to quit, there were modest cessation rates $\left(19 \%^{26} 36 \%{ }^{25}\right)$.

SMOKESCREEN PROGRAM

Every patient should be asked if they smoke and should be advised about their smoking at each visit. Many doctors' past failures with patients have resulted from trying to persuade smokers who are not yet ready to quit. The "Stages of change model" ${ }^{30}$ recognises that at any one time there are $20 \%$ of smokers in the general population who are ready to quit, $40 \%$ who are unsure about whether to quit, and $40 \%$ who are not ready to quit. ${ }^{31}$ An assessment needs to be made about patients' readiness to quit so that the appropriate intervention can be delivered. The first step when intervening with smokers is to ask whether they are ready to stop smoking. Just because the patient with IHD has been advised to quit, does not mean that he or she is ready to stop and will be successful.

The next step is to allocate the patient to one of the three readiness groups. This is accomplished by asking: "How do you feel about your smoking?"32 This open ended question raises the issue of smoking in a non-confrontational way and leads to dialogue in which readiness to quit can be determined. If it is still unclear, then asking: "Are you ready to quit now?" provides a more definitive answer.

When the doctor and patient have ascertained stage of readiness, the next step is to provide the appropriate brief smoking intervention. Patients who are not ready to quit, want to smoke and they do not acknowledge the negative aspects of smoking as more important. Personalising smoking as a major risk of heart disease and emphasising the benefits of quitting encourages patients not ready to quit to consider the pros and cons of smoking. The advice should be no more than a couple of minutes as these smokers are not ready to change at this time.

Patients who are unsure or ambivalent about smoking, have concerns about the effect of smoking on health, but are also aware of the disadvantages to quitting. The aim is to motivate smokers who are unsure to change and become ready to quit. A technique called brief motivational interviewing $^{33}$ is useful in enabling the unsure patient to weigh the pros and cons of smoking so that a decision can be made to try and quit. The steps of motivational interviewing are to ask about what the patient likes about smoking, then ask what the patient does not like about smoking. Then 
summarise the patient's pros and cons of smoking and ask: "Where does this leave you now?"

A key principle of motivational interviewing is that the patient takes responsibility for the smoking problem. Patients are more likely to make a decision to stop smoking if they have reached it on their own. The time spent with unsure patients is five minutes and self help materials available from health organisations can be provided.

Common barriers to quitting include concern about withdrawal, high dependence on nicotine, low motivation to quit, excessive alcohol use, and a family, work, and social environment with a predominance of smokers. If the physician assists in the change process so that the patient moves from being unsure to attempting to quit, then the consultation is regarded as successful. The next stage is to advise about quitting.

Physicians think that all patients are ready to quit if they advise them to stop smoking. Clearly this is not the case, although there may be compelling cardiac and other reasons why the patient should stop. Interventions in the 1980s were designed mainly for the small group of smokers ready to quit. These smokers have made a serious commitment to try and stop smoking and appreciate that the disadvantages of smoking outweigh the benefits.

Patients who are ready to stop require an active intervention consisting of cognitive and behavioural strategies as well as nicotine replacement to help them overcome withdrawal symptoms. As the cardiologist has limited time to advise on smoking, there are three main issues to discuss. First, it is important for the patient to set a date to stop smoking. Second, give the smoker a booklet that outlines many of the strategies for successful quitting including activities that distract, avoid, and delay smoking. Finally, available time should be spent explaining the effective use of nicotine replacement.

\section{Nicotine replacement}

Two thirds of patients experience some withdrawal symptoms such as severe craving to smoke, insomnia, dizziness, loss of concentration, nervousness, tiredness, headaches, lightheadedness, and irritability. Withdrawal symptoms are signs of recovery, and the worst of these symptoms subsides in the first week of stopping and most symptoms have disappeared in 10-12 days. Patients who smoke more than 15 cigarettes per day are likely to be nicotine dependent and concerned about suffering withdrawal symptoms. Nicotine gum and patches are valuable aids for quitting. Nicotine gum and transdermal nicotine patches are available over the counter in many countries. It is advisable to caution patients not to smoke while using these aids as this is predictive of failure to quit smoking. ${ }^{34}$ Although both gum and patches are efficacious, in general, the patch is preferable for routine clinical use. Use of the active patch doubles success rates compared to placebo. ${ }^{35}$ Transdermal nicotine has been shown to be safe for patients with stable IHD, ${ }^{36} 37$ and does not affect angina frequency, overall cardiac symptom status, arrhythmias, or episodes of ischaemic ST segment depression. ${ }^{36} \mathrm{~A}$ nicotine nasal spray is available on prescription (in the UK and USA), and a nicotine inhaler will be available soon. Providing advice on quitting for "ready" smokers will add another 5-10 minutes to the consultation.

The smoking status of all cardiac patients should be assessed and the appropriate brief intervention offered to smokers according to their readiness to quit. The patient who has a clinical illness is likely to be motivated to change, and the consultation is a powerful setting to advise about quitting. Reducing the proportion of the population that smokes should be a multipronged campaign including the cardiologist and general practitioner who proactively encourage their patients to quit, antismoking advertising, increasing the price and taxes on cigarettes, and primary prevention initiatives among children and adolescents.

R RICHMOND

School of Community Medicine,

University of New South Wales,

Kensington NSW 2052, Australia.

email:R.Richmond@unsw.edu.au

1 US Departmentt of Health and Human Services. The health benefits of smoking cessation. A report of the Surgeon General. Washington, DC: USDHHS, ing cessation. A report of the Surgeon General. Washington, DC: USDHHS, Centers for Disease Control.

2 US Department of Health and Human Services. The health benefits of smoking cessation. A report of the US Surgeon General. Washington, DC: USDHHS Centers for Disease Control. Office of Smoking and Health, 1990. DHHS Publication (CDC) 90-8416.

3 Anderson KM, Wilson PW, Odell PM, et al. An updated coronary risk profile: a statement for health professionals. Circulation 1991;83:356-62.

4 Shinton R, Beevers G. Meta-analysis of relation between cigarette smoking and stroke. BMF 1989;298:789-94.

5 Parish S, Collins R, Peto R, et al, for the International Studies of Infarct Survival (ISIS). Cigarette smoking, tar yields, and non-fatal myocardial infarction: 14000 cases and 32000 controls in the United Kingdom. BMF 1995;311:471-7.

6 Smith R. Richard doll at 85 [editorial]. BM7 1997;315:1031.

7 DeBusk RF, Miller NH, Superko HR, et al. A case-management system for coronary risk factor modification after acute myocardial infarction. Ann Intern Med 1994;120:721-9.

8 Ockene JK, Hosmer DW, Williams JW, et al. Factors related to patient smoking status. Am f Public Health 1987;77:356-7.

9 Frid D, Ockene IS, Ockene JK, et al. Severity of angiographically proven coronary artery disease predicts smoking cessation. Am f Prev Med 1991;7: $131-5$.

10 Hay DR, Turbott S. Changes in smoking habits in men under 65 years after myocardial infaction and coronary insufficiency. Br Heart $\mathcal{F}$ 1970;32:73840

11 Wilhelmsson C, Vedin JA, Elmfeldt D, et al. Smoking and myocardial infarction. Lancet 1975;i:415-20.

12 Hasdai D, Garratt KN, Grill DE, et al. Predictors of smoking cessation after percutaneous coronary revascularization. Mayo Clinic Proc 1998;73:205-9.

13 Vlietstra RE, Kronmal RA, Oberman A, et al. Effect of cigarette smoking on survival of patients with angiographically documented coronary artery disease: report from the CASS registry. $\mathscr{F A M A} 1986 ; 255: 1023-7$.

14 Ockene IS, Miller NH, Houston N. Cigarette smoking, cardiovascular disease, and stroke: a statement for healthcare professionals from the Ameriease, and stroke: a statement for healthcare profess
can Heart Association. Circulation 1997;96:3243-7.

15 Patten CA, Bruce BK, Hurt RD, et al. Smoking cessation following a cardiac rehabilitation program. Fournal of Prevention and Intervention in the Community 1996;13:161-76.

16 Salonen JT. Stopping smoking and long-term mortality after acute myocardial infarction. Br Heart $\mathcal{f}$ 1980;43:463-9.

17 Fielding JE. Smoking: health effects and control. $N$ Engl f Med 1985; 313:491-8.

18 Samet J. Health benefits of smoking cessation. Clin Chest Med 1991;12:66979.

19 McKenna KT, Maas F, McEniery PT. Coronary risk factor status after percutaneous transluminal coronary angioplasty. Heart Lung 1995;24:207-12.

20 Voors AA, van Brussel BL, Plokker HW, et al. Smoking and cardiac events after venous coronary bypass surgery. A 15-year follow-up study. Circulation 1996;93:42-7.

21 Fiore MC, Bailey WC, Cohen SJ, et al. Smoking cessation. Clinical practice guideline No 18. Rockville, MD: US Departmentt of Health and Human guideline No 18. Rockville, MD: US Departmentt of Health and Human
Services, Public Health Service, Agency for Health Care Policy and Research, 1996. AHCPR Publication 96-0692.

22 Russell MAH, Wilson C, Taylor C, et al. Effect of general practitioners' advice against smoking. BMf 1979;2:231-5.

23 Russell MAH, Merriman R, Stapleton J, et al. Effect of nicotine chewing gum as an adjunct to general practitioners' advice against smoking. $B M \mathcal{F}$ 1983;287:1782-5.

24 Wilson DM, Taylor DW, Gilbert JR, et al. A randomized trial of a family physician intervention for smoking cessation. $\mathcal{F A M A} 1988 ; 260: 1570-4$

25 Richmond RL, Austin A, Webster IA. Three year evaluation of a programme by general practitioners to help patients stop smoking. BMf 1986; 292:803-6.

26 Richmond RL, Makinson R, Kehoe L, et al. One year evaluation of general practitioners' use of three smoking cessation programmes. Addict Behav practitioners use

27 Hurt RD, Lowell CD, Fredrickson PA, et al. Nicotine patch therapy for smoking cessation combined with physician advice and nurse follow-up: one-year outcome and percentage of nicotine replacement. $¥ A M A$ $1994 \cdot 271 \cdot 595-600$

28 Ockene JK, Kristeller J, Pbert L, et al. The physician-delivered smoking intervention project: can short-term interventions produce long-term effects for a general outpatient population? Health Psychol 1994;13:278-81.

29 Royal Australasian College of Physicians. Physicians can help patients to stop smoking. Fellowship Affairs 1993;12:15-16.

30 Prochaska JO, DiClemente CO. Towards a comprehensive model of change. In: Miller WR, Heather N, eds. Treating addictive behaviors: Processing change. New York: Plenum, 1986:3-27.

31 Velicer WF, Fava JL, Prochaska JO, et al. Distribution of smokers by stage in three representative samples. Prev Med 1995;24:401-11.

32 Mendelsohn CP, Richmond RL. GPs can help their patients to stop smoking. Med F A ust 1992;157:463-7.

33 Rollnick S, Bell A. Brief motivational interviewing for use by the non-specialist. In: Miller W, Rollnick S, eds. Motivational interviewing: Preparing people for change. New York: Guildford, 1991:203-13. 
34 Kenford SL, Fiore MC, Jorenby DE, et al. Predicting smoking cessation: Kenford SL, Fiore $M C$, Jorenby $\mathrm{DE}$, et al. Predicting smoking cessation: who

35 Richmond RL, Kehoe L, Cesar de Almeida Neto A. Effectiveness of a 24-hour transdermal nicotine patch in conjunction with a cognitive behavioural programme: one year outcome. Addiction 1997;92:27-31.
36 Working Group for the Study of Transdermal Nicotine in Patients with Coronary Artery Disease. Nicotine-replacement therapy for patients with coronary artery disease. Arch Intern Med 1994;154:989-95.

37 Joseph AM, Norman SM, Ferry LH, et al. The safety of transdermal nicotine as an aid to smoking cessation in patients with cardiac disease. $N$ Engl f Med 1996;335:1792-8.

\section{STAMPS IN CARDIOLOGY}

\section{Aspirin}

In the 17th and 18th centuries cinchona bark from South America was the preferred treatment for pain and fevers but in 1763 the Reverend Edward Stone of Chipping Norton found that bark of the willow tree, Salix alba, was an effective substitute. By 1829 the active compound had been isolated and named "salicin". In 1838 salicylic acid was prepared from salicin and it was also prepared from the meadowsweet, Spiraea ulmaria. Salicylic acid was a good
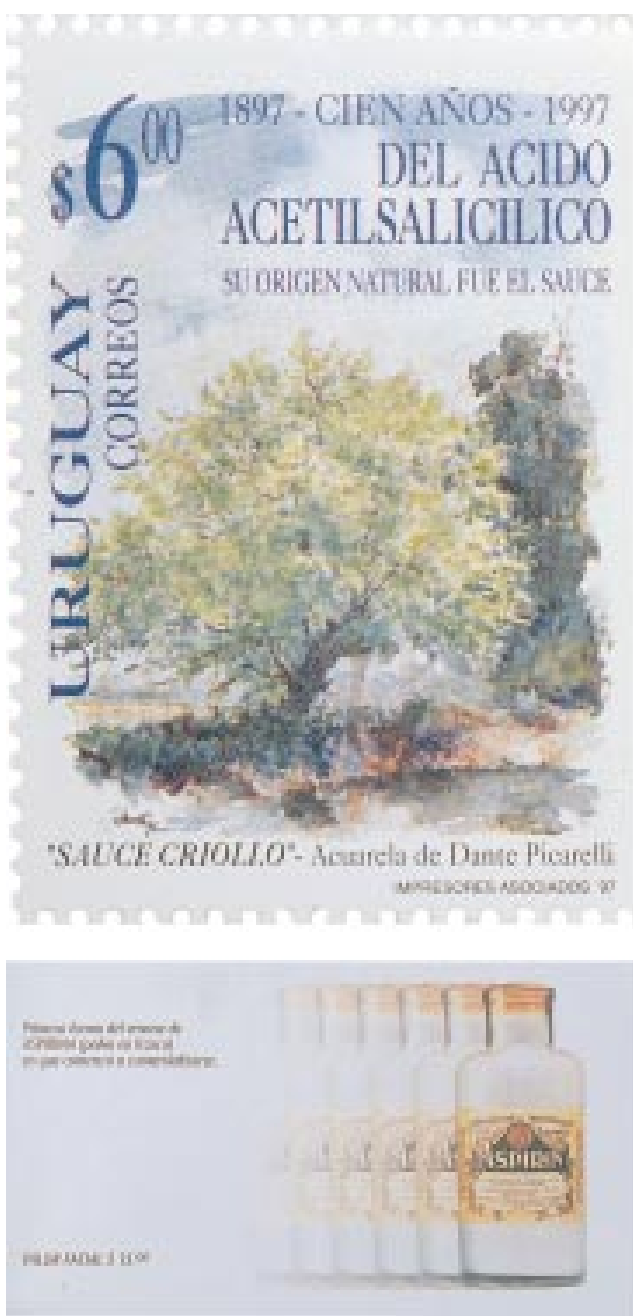

analgesic and antipyretic; by 1860 it had been synthesised and later 24000 kilograms a year were being produced. However, it irritated the mouth and stomach and these side effects led to the search for a better compound. This was achieved at the Bayer laboratories in Leverkusen by the chemist Dr Felix Hoffmann (1868-1946) on 10 August 1897 when he produced a pure and stable form of acetylsalicylic acid. It was a tremendous success and Bayer's trade name, "Aspirin" became world famous. The name comes from "a" for acetyl, "spir" from Spiraea, and "in" as a common ending for a drug.

The only stamp issued on this theme comes from Uruguay in 1997 to mark the centenary of the synthesis of acetylsalicylic acid. A booklet of two stamps was issued and the front cover depicts Dr Felix Hoffmann, a branch of the willow tree, and his signature taken from his laboratory record of 10 August 1897. Bayer supplied aspirin to dispensing chemists in 250 g glass bottles (circa 1899), which are pictured inside the booklet, and the back cover bears the Bayer logo.

M K DAVIES A HOLLMAN
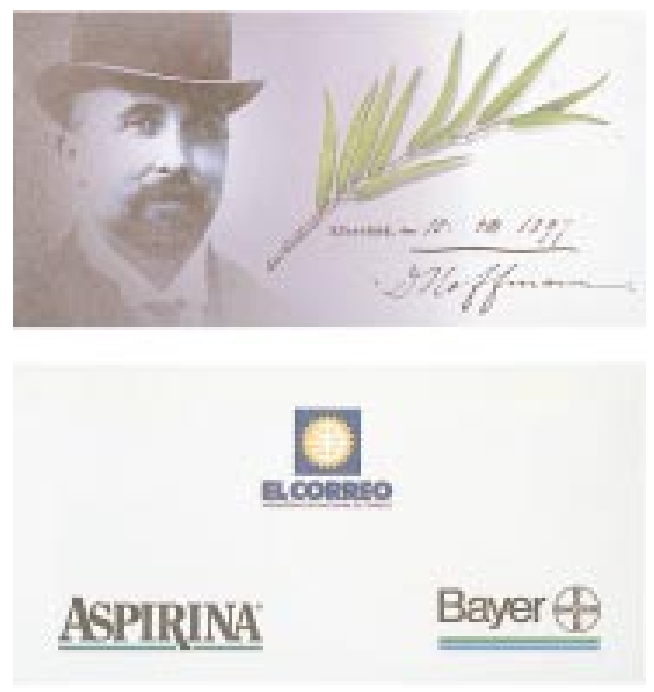